\title{
Ensino Remoto de Educação Física: A Experiência com Jogos Interclasses Digitais em uma Escola Pública do Ceará
}

\author{
Valdeir L. P e Silva ${ }^{1}$, Priscila B. David ${ }^{1}$ \\ ${ }^{1}$ Instituto UFC Virtual - Programa de Pós- Graduação em Tecnologia educacional- \\ Universidade Federal do Ceará (UFC) \\ Caixa Postal: 60455-760 - Fortaleza - CE - Brazil \\ valdeirlira@hotmail.com, priscila@virtual.ufc.br
}

\begin{abstract}
The paper approaches the need for reformulation on the traditional interclass games competition promoted by public high schools considering the current pandemic scenario. The objective is to discuss alternative methodologies that include digital games in such a competition. The research's methodology is a microethnography, aiming to understand the contribution of the digital interclass competition to the teaching of physical education. The study points out that in times of social isolation, the model reached the school community successfully, including students with a lack of interest in the traditional interclass games, in addition to challenging the physical education teacher to invest on her own formation process.
\end{abstract}

Resumo. $O$ artigo aborda a necessidade de reformulações dos modelos tradicionais de jogos interclasses, promovidos por escolas públicas de ensino médio, considerando o cenário pandêmico atual. $O$ objetivo é discutir a adoção de metodologias que contemplem jogos digitais nesse tipo de competição. A metodologia do estudo constitui uma microetnografia, visando compreender a contribuição do modelo de interclasses com jogos digitais ao ensino de Educação Física. O estudo aponta que em tempos de isolamento social, o modelo teve um boa adesão por parte da comunidade escolar, inclusive alcançando estudantes que não se identificavam com os modelos tradicionais de jogos interclasses, além de desafiar a professora de educação física a investir em seu próprio processo de formação.

\section{Introdução}

Em março 2020, o mundo foi surpreendido com a identificação do vírus SARS-CoV-2, notificado pela Organização Mundial de Saúde por meio de decreto [Velavan and Meyer 2020], o que gerou o alerta de uma doença contagiosa de grandes proporções, logo caracterizada pelas autoridades sanitárias como uma pandemia. Os principais sintomas clínicos citados eram: lesionamento das vias respiratórias superiores podendo evoluir para as vias respiratórias inferiores, causando desta forma efeitos como: tosses, falta de ar, dores de cabeça, falta de ar, febre acima de $38^{\circ} \mathrm{C}$, aumento de linfonodos laríngeos, excesso de secreção mucoide [Rothan and Byrareddy 2020].

Diante do cenário da pandemia, medidas de isolamento social foram implementadas globalmente, inclusive no Brasil, tendo em vista reduzir o risco de 
contaminação pelo vírus. No dia 16 de março de 2020, a Secretaria de Educação do Estado do Ceará (SEDUC) decidiu, por meio do decreto $\mathrm{n}^{\circ} 33.510$, publicado no Diário Oficial do Estado (DOE), a suspensão das aulas presenciais, inicialmente planejada para um período de 15 dias. Não obstante, o decreto foi estendido reiteradas vezes, até o mais recente, em 12 de junho de 2021 de $\mathrm{n}^{\mathrm{o}} 34.103$.

A situação então vivenciada, exigiu por parte dos governantes e de suas secretarias de educação novas soluções para as atividades educacionais. Aulas presenciais e atividades práticas, então suspensas, precisavam ser repensadas, dando origem ao chamado Ensino Remoto Emergêncial (ERE) [Hodges et al. 2020], sustentado na COVID-19, sistema que permitiria que os professores ministrassem suas aulas em formato on-line com a flexibilidade de ensinar e aprender por meio das tecnologias digitais.

Diante deste cenário, os professores de educação física viram-se desafiados pelo ERE, pela própria natureza da disciplina, com grande peso em atividades essencialmente práticas, já que, no momento da atividade física prática o aluno reconhece seu corpo, por meio de atividades como jogos, exercícios e brincadeiras. Dentre essas atividades, uma se destaca entre os estudantes de ensino médio: os jogos interclasses. Tratam-se de eventos esportivos que promovem a competição entre os estudantes, nas diversas categorias do esporte como: Futsal,Volei, Handebol, Atletismo, promovendo a interação entre diversas turmas e séries. É importante destacar que este tipo de evento possui particularidades no que diz respeito às regras, período de duração, materiais disponíveis e o respeito ao calendário escolar específico de cada instituição [Revertido et al. 2008]. Anualmente, tais atividades eram vivenciadas no formato presencial pelos estudantes da escola alvo desta pesquisa.

Não obstante, o contexto da pandemia resultou em 2020 na suspensão da competição em seu formato tradicional, isto é, presencialmente. Surge, então, a seguinte questão: como ressignificar as competições de jogos interclasses durante a pandemia da COVID-19, de forma remota, garantindo e mantendo o envolvimento dos estudantes com as atividades escolares, em especial com o ensino de Educação Física?

O presente estudo tem como objetivo analisar a transição de jogos interclasses do modo presencial para o remoto, mediante o uso de jogos digitais, tendo como alvo o engajamento e a participação dos estudantes na competição, ainda que a distância. $\mathrm{O}$ artigo está dividido em quatro seções. Após esta introdução, apresentaremos a metodologia do estudo, seguida dos resultados produzidos e discussão à luz da teoria. Por fim, faremos as conclusões do estudo e indicaremos futuras pesquisas sobre o tema.

\section{Metodologia}

Este trabalho caracteriza uma pesquisa de natureza exploratória, cujos procedimentos envolveram uma investigação microetnográfica. Segundo McDermott, Gospodinoff \& Aron (1978) e Erickson (1992) a microetnografia permite a análise de uma situação local e engajamentos interacionais, constituindo a experiência social do experimento, assim, permite que se conduza uma metodologia com detalhes minuciosos. Por se tratar de um modelo novo, este tipo de lógica de investigação é considerada, pelos autores, a mais adequada para a obtenção de dados significativos, não perceptíveis em outras lógicas investigativas.

\section{a) Local da pesquisa e Sujeitos}


Participaram da pesquisa 92 estudantes de ensino médio técnico, inscritos na competição dos jogos interclasses, e a professora de educação física da Escola Estadual de Ensino Profissionalizante omitido para submissão, localizada na cidade de FortalezaCeará/Brasil. O estudo foi conduzido no período de abril a julho de 2021.

A Escola omitido para submissão oferta regularmente cinco cursos técnicos nas áreas de: Administração, Logística, Mineração, Petróleo e Gás, e Portos. Trata-se de uma escola de ensino médio com 486 alunos matriculados. Nesse sentido, o universo de participantes da pesquisa representou, aproximadamente, 19\% do público discente da instituição. As inscrições para os jogos interclasses se deram por meio de um formulário eletrônico, disponibilizado via Google Forms por meio do qual os alunos poderiam escolher até duas dentre três opções de jogos on-line: Ludo King, Gartic e 8 Ball Pool.

\section{b) A microetnografia como lógica de investigação}

A microetnografia como lógica de investigação permite que o pesquisador (etnógrafo) deixe de lado qualquer conhecimento prévio e se engaje na busca por uma compreensão aprofundada sobre o evento em análise, o que endossa a relevância de tal metodologia para este estudo, na medida em que busca compreender como se deu o processo de reformulação dos jogos interclasses, do modo presencial para o remoto. Para que o objeto fosse analisado ignorando qualquer conhecimento prévio, devido à afetividade do pesquisador com a instituição, optou-se pela cisão dos papéis dos autores, quando um se concentrou numa análise interativa, enquanto o outro absorveu caráter analítico e observador. De acordo com Green e Castanheira (2003):

\section{[...] Assim, para conhecer qualquer fragmento de vida ou processo que é socialmente relevante para um grupo, ou para alguns membros em particular, o etnógrafo precisa seguir como os membros apropriam, transformam, (re)formulam e usam (ou não) o que foi proposto e construído tanto em um evento em particular como em diferentes momentos, ações e contextos sociais (p.7).}

Como parte da condução da pesquisa microetnográfica, optou-se como mecanismo de coleta de dados pela observação participante, em virtude de o pesquisador/etnógrafo também ser professor na instituição em tela. Segundo Spradley (1980) a observação participante pode acontecer de duas formas: de forma passiva, com o objetivo de apreender conhecimentos tendo em vista compreender a vida de um grupo social, ou ativa, na perspectiva de ser um observador participante no cenário de investigação. Como parte das observações realizadas é de fundamental importância o registo dos fatos observados em diário de campo para posterior análise e contraste de dados.

Adicionalmente, também foram conduzidas entrevistas não estruturadas. Esse tipo de entrevista se caracteriza pela possibilidade de deixar os entrevistados à vontade na forma de apresentação de suas respostas [Laville e Dione 1999], viabilizando uma riqueza de detalhes na falas dos entrevistados, com elementos não esperados. Foram entrevistados (as), desta maneira: a professora responsável pelo evento, a diretora, como representante do núcleo gestor escolar e doze alunos. A escolha dos alunos seguiu alguns critérios, na tentativa de contempletar a maior diversidade de público. Entre os critérios em destaque, está a participação de alunos que se fizeram presentes em edições anteriores, alunos que nunca tinham participado do evento e alunos de todas as séries. A partir desta amostragem, busca-se um parâmetro comparativo entre os modelos tradicionais e os novos métodos propostos, por parte dos alunos veteranos. Enquanto 
isto, a inclusão de alunos que nunca haviam participado do modelo tradicional, traz ao estudo a possibilidade de análise de um nicho que não possui expectativas.

Além disso, também foram consultados documentos gerados durante a competição. A recolha de tais documentos, envolveu: as tabelas dos jogos, os contratos de conduta estabelecidos via WhatsApp, documentos gerados em reuniões anteriores de conselho de classe da escola, e os prints de participação e resultados que eram requisitos do regulamento dos jogos interclasses. A Figura 1 reúne as etapas da metodologia conduzida neste estudo.

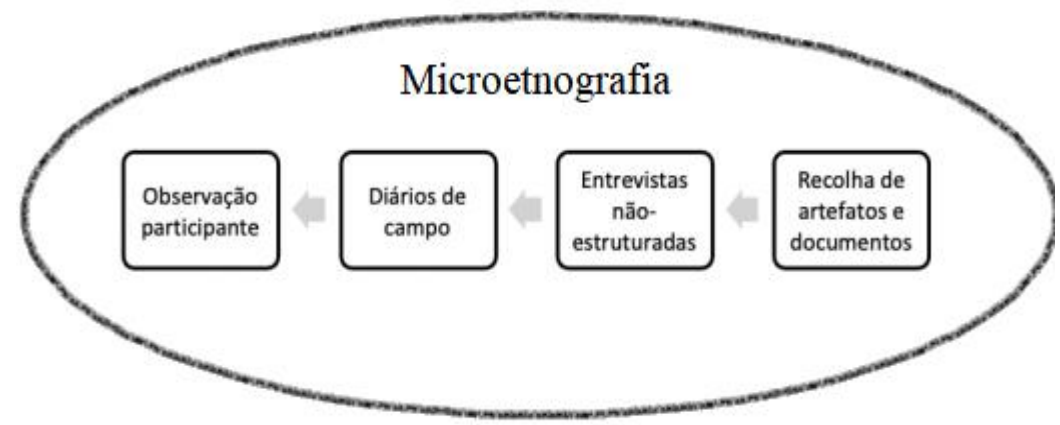

Figura 1. Metodologia e etapas da investigação

\section{c) O processo de decisão de escolha dos jogos}

A decisão a respeito dos jogos digitais a serem ofertados durante a competição passou por uma consulta pública prévia à comunidade escolar e envolveu: professores, estudantes e funcionários, os quais opinaram sobre possíveis jogos digitais que poderiam ser utilizados durante o evento. A consulta prévia foi uma proposta da professora de Educação Física, segundo a qual não possuía capacitação para a escolha de jogos educativos digitais, tendo em vista o novo formato da competição.

\footnotetext{
"Tive que pedir ajuda aos meninos por meio do WhatsApp porque eu não conhecia os jogos, foram muitos jogos, obtive uma lista com 90 jogos dos quais 3 eu selecionei por conseguir relacionar os jogos à competências estabelecidas pela Base Nacional Comum Curricular, sem falar nos jogos que tinham conteúdos como violência, desrespeito à condição humana que de imediato foram eliminados". (Depoimento 1 da professora de Educação Física).
}

Assim, foram selecionados os três jogos, dentre os mais citados nos formulários, os quais serão descritos a seguir.

Ludo King. Jogo de tabuleiro que pode ser jogado por até 4 participantes, com o objetivo de complementar o caminho do tabuleiro através dos pinos (Figura 2). A movimentação dos pinos exige planejamento para que os jogadores não sejam eliminados pelos adversários. Esse jogo contempla o desenvolvimento das competências de linguagens, códigos e suas tecnologias, através da construção de argumentos, capacidade de relacionar informações, representadas em diferentes formatos, e conhecimentos disponíveis em situações concretas para construir uma argumentação consistente. 


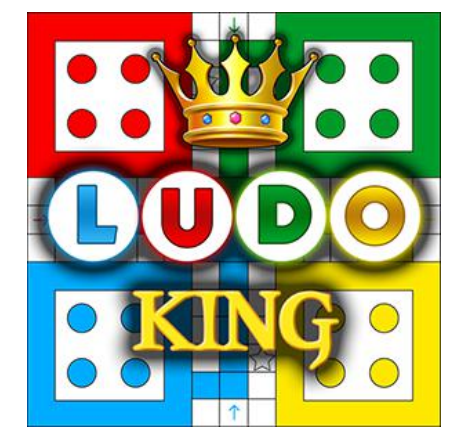

Figura 2. Logo do Ludo King

Gartic. Este é um jogo de desenhos on-line (Figura 3), cujo objetivo é acertar o que o outro jogador está desenhando. Dentro da competência de linguagem e códigos, busca-se compreender e usar os sistemas simbólicos das diferentes linguagens como meios de organização cognitiva da realidade, pela constituição de significados, expressão, comunicação e informação.

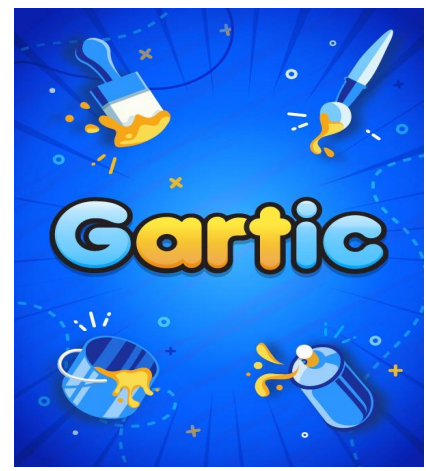

Figura 3. Logo do Gartic

8 Ball Pool. Jogo de sinuca virtual considerado muito divertido e até viciante (Figura 4). A exemplo dos anteriores também pode contribuir para a área de linguagem e códigos dentro das competências que envolvem: selecionar, organizar, relacionar e interpretar dados e informações representados em diferentes formatos, tendo em vista a tomada de decisões e a resolução de situações-problema.

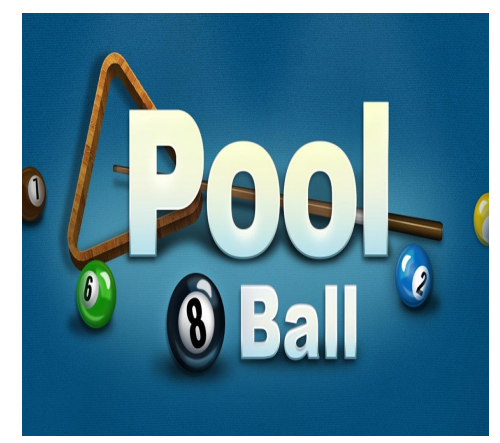

Figura 4. Logo do 8 Ball Pool

A adesão aos jogos deu-se nas seguintes proporções: 60 alunos optaram pelo Ludo King, representando 65,2\% do público total; 59 alunos escolheram o Gartic, performando 64,1\%; e no jogo 8 Ball, 49 alunos aderiram, caracterizando 53,3\%. Cada Jogo apresentava 3 vencedores, sendo o campeão de cada categoria contemplado com 
um cartão presente do Google Play, como forma de incentivo à inclusão digital dos alunos em aplicativos, jogos, filmes e muitos mais. Vale ressaltar que, o somatório de porcentagem é superior a $100 \%$, visto que o aluno poderia optar por mais de um jogo.

\section{d) Avaliação dos jogos interclasses em formato digital}

Finalizada a competição, decidiu-se realizar uma consulta aos alunos por meio um novo formulário do Google Forms para a avaliação da qualidade da competição esportiva. As perguntas possuíam estrutura aberta na possibilidade de se avaliar nas mais diversas falas diferentes pontos de vista, consistindo de 4 questões que foram dispostas das seguintes formas:

Q1. O que você achou do interclasse?

Q2. Quais contribuições este tipo de evento trouxe para você enquanto estudante?

Q3. O que deu certo? O que precisa melhor?

Q4. Deixe sugestões para os próximos eventos

A análise das respostas deu-se mediante a gravação do momento da leitura dos formulários de avaliação. A professora responsável pelo evento teve a iniciativa de juntar os pontos mais relevantes para o novo evento proposto e apresentou desta forma ao núcleo gestor escola.

\section{Resultados e Discussões}

Os resultados apresentados nesta seção congregam os elos estabelecidos entre os eventos observados, os diários de campo, os documentos da competição consultados durante a pesquisa e as entrevistas realizadas. As diversas fontes de dados viabilizaram a realização de uma análise contrastiva tendo em vista a identificação de pontos ricos e elaboração de casos-exemplo [Green et al. 2005] que demonstrem os resultados alcançados no estudo.

\section{a) Adesão dos estudantes ao novo evento}

A participação dos estudantes no evento aconteceu nas seguintes proporções: dos 92 alunos, 45 alunos estavam cursando o primeiro ano do ensino médio; 24 alunos cursavam o segundo ano, e 23, o terceiro ano. O Gráfico 1, a seguir, apresenta os resultados referentes a esta distribuição.

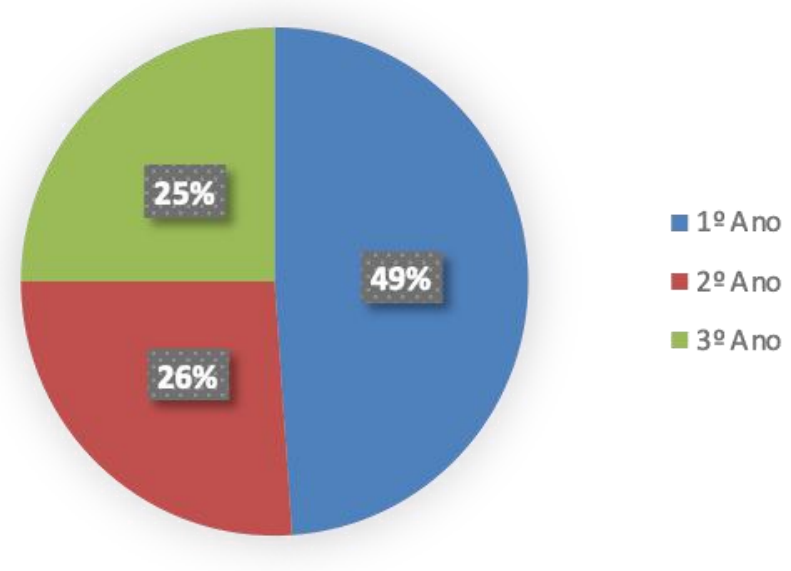




\title{
Gráfico 1. Participação dos alunos por série
}

Tal distribuição da participação dos alunos encontra-se justificada na fala da professora de Educação Física, a partir de um trecho da transcrição da entrevista por ela concedida.

\begin{abstract}
"Como o evento não era obrigatório, achei um número bastante significativo e até desafiador para mim na construção das tabelas, por muitos momentos me vi só, frente à uma área que não dominava que era a de tecnologias educacionais na educação física. Sem dúvidas os alunos do primeiro são os mais interessados porque cada vez mais esta geração gosta de jogos digitais, sem falar que nunca tiveram a oportunidade de participar de um interclasse presencial, talvez já estejam acostumados com o novo normal." (Depoimento 2 da professora de Educação Física).
\end{abstract}

Uma análise documental de edições anteriores dos jogos interclasses (presenciais), indica que o número de inscrições por série era mais uniforme entre as três séries do ensino médio, o que revela um dado novo na edição dos jogos interclasses em formato digital, com maior adesão pelos estudantes do $1^{\circ}$ ano. Comparativamente à edição de 2019, donde o Futsal era predominante (40 alunos inscritos), somente 10 alunos eram de turmas da $1^{\text {a }}$ série, correspondendo a $25 \%$ do total, bem diferente do que foi observado no modelo digital, com expressiva participação dos estudantes da série inicial. A professora atribui este fenômeno a certo sentimento de inferioridade, provocado pela disparidade corporal entre os jovens das diferentes séries, já que os mais franzinos sentem-se inferiores aos de maior porte físico. A professora ressalta ainda que na modalidade digital essas diferenças tornam-se irrelevantes, não sendo vistas como obstáculo para competir e obter êxito.

\section{b) 4.2 A importância do contrato de conduta no Ciberespaço}

Mediante a possibilidade de fraudes, invasões cibernéticas e a possibilidade de ofensas por sujeitos não identificados, a professora determinou regras que, segundo a análise, foram fundamentais para o sucesso do evento. A figura a seguir apresenta como se deu o contrato de conduta e o estabelecimento de regras. 


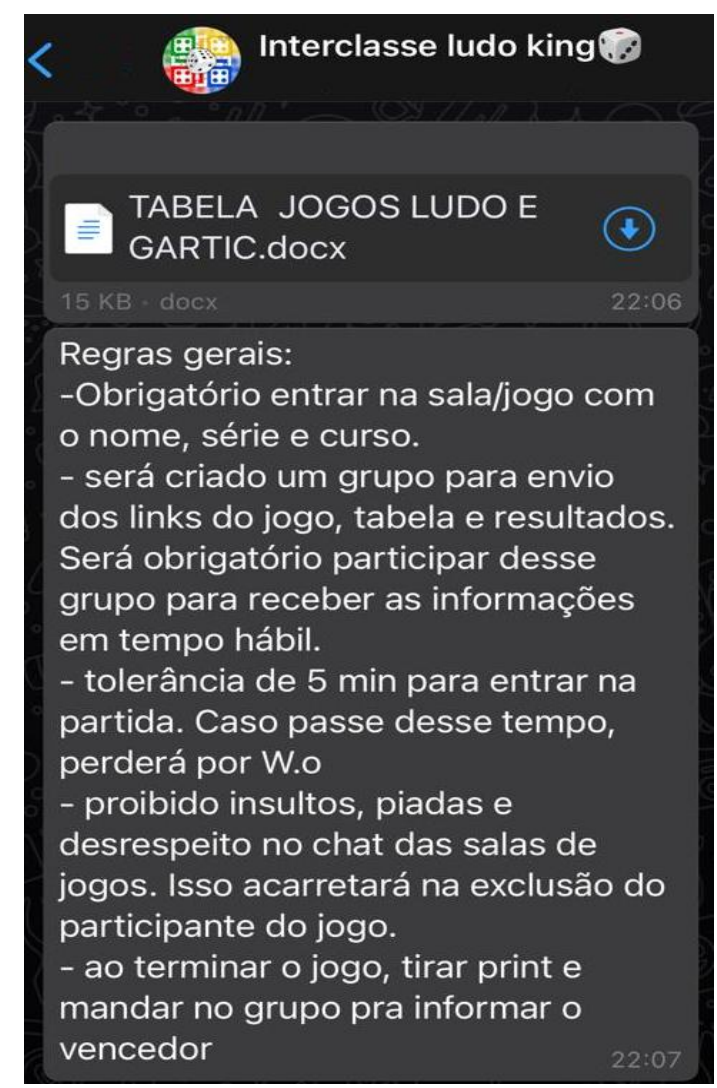

Figura 5. Regras da Competição Estabelecidas via WhatsApp

Para suprir o problema das invasões cibernéticas, a professora estabeleceu que os alunos entrassem na sala do Google Meet com nome e suas respectivas turmas para uma identificação mais segura, o que permitiu que este tipo de fenômeno fosse evitado.

Durante os jogos, não foi notado nenhum episódio de ofensas entre os participantes. Como uma das regras era a produção de prints de tela para se comprovar a participação dos alunos, este tipo de técnica inibia a ofensa por parte dos jogadores.

Conforme o núcleo gestor da escola, o estabelecimento de regras é um dos pontos fundamentais para a promoção de um evento de sucesso; em um dos seus relatos, a diretora afirma que já foi pensado em retirar o interclasse da programação escolar, porque criava muitos conflitos na escola quando acontecia no formato presencial.

\section{c) A implementação do novo modelo de jogos interclasses na formação pedagógica da professora de Educação Física}

Segundo a professora de Educação Física da escola, durante a sua formação acadêmica não foram ministradas temáticas como a utilização de ferramentas tecnológicas para a ministração de aulas no ensino de educação física. A professora afirma que a formação docente nessa área carece de metodologias atualizadas e condizentes com o contexto atual dos estudantes, amplamente integrados e conectados às tecnologias digitais.

Ao ser questionada sobre quais teriam sido as maiores aprendizagens no processo de adaptação dos jogos interclasses, do modelo presencial para o remoto, a professora levanta pontos importantes, destacados a seguir:

- A necessidade de entender mais sobre jogos on-line; 
- Estabelecer ligação entre jogos on-line e as competências e habilidades sugeridas pela Base Nacional Comum Curricular;

- Organizar uma metodologia para o campeonato que evite fraudes e desrespeitos;

- Adaptação de modelos tradicionais de tabelas de jogos para o formato digital.

\section{d) Pontos positivos e negativos sobre os jogos interclasses digitais na visão dos participantes da pesquisa}

Com base no formulário de avaliação divulgado junto aos estudantes participantes ao final da competição, via do Google Forms, foi possível extrair suas impressões sobre como foi a experiência dos jogos interclasses em formato digital. Os pontos mais frequentemente abordados foram:

O evento contempla alunos que não se identificam com os modelos presenciais de interclasses; os jovens relataram que muitas vezes possuíam vergonha das suas limitações físicas ou da ausência de habilidades;

Durante a pandemia, os alunos, até então, não tinham tido a oportunidade de interagir com outras turmas e, durante o evento, foi possível conhecer e interagir com novos membros;

Os alunos colocaram o pedido de continuidade do novo modelo, que este não precisava competir com o modelo tradicional, mas que poderia ser complementar.

Para a professora de educação física, os principais pontos positivos foram: a possibilidade de se realizar muitos jogos ao mesmo tempo, a menor necessidade de colaboradores como: juízes, organizadores, fiscalizadores, problema frequente nas competições presenciais, e que foi suprido no formato digital.

\section{e) Pontos negativos sobre os jogos interclasses digitais na visão dos} participantes da pesquisa

O único fator negativo presenciado pelos alunos foi a dependência de Internet e de aparelhos tecnológicos, segundo os quais, há aparelhos que favorecem o desempenho dos jogadores. Nesse quesito, deixaram como sugestão que o modelo de interclasse digital poderia acontecer no laboratório de informática, em edições futuras, de forma a garantir iguais condições de uso em aparelhos tecnológicos.

\section{f) O impacto do projeto e projeções futuras}

A partir da experiência com os jogos interclasses em formato digital desenvolvido na escola, em tela neste estudo, e na divulgação do evento e resultados, outras escolas tomaram conhecimento do evento e pediram orientações pedagógicas para seguirem com projetos semelhantes.

É de intenção da comunidade escolar a inserção do novo formato de evento no calendário escolar, como uma proposta para se trabalhar conteúdos interdisciplinares. O sucesso do evento também despertou em outros professores o desejo pela competição de conteúdos específicos dentro de suas disciplinas.

O evento será pauta da próxima semana pedagógica dentro da escola, a ser realizada no período de 23 a 27 de janeiro de 2022. Outras escolas foram convidadas 
para debaterem sobre o tema, como legado da inclusão de novas práticas pedagógicas na educação básica, mais especificamente na educação física.

\section{Conclusões}

O objetivo deste estudo foi analisar a transição de jogos interclasses do modo presencial para o remoto, em uma escola de ensino médio localizada na cidade de Fortaleza-CE, mediante a adoção de jogos digitais, tendo como alvo o engajamento e a participação dos estudantes na competição. Para o alcance deste objetivo foi conduzida uma pesquisa de natureza microetnográfica, que contou com a participação de 92 estudantes, a professora de educação física responsável pelo projeto e a diretora da escola.

O estudo evidenciou pontos relevantes como: a necessidade de formação de professores de educacao física em tecnologias digitais, voltadas às práticas docentes. Tal questão pode ser o ensejo para discussões no meio acadêmico, no que tange a possíveis inserções no currículo do professor de educação física, que contemplem tais habilidades, diante dos avanços tecnológicos e seus impactos no campo educacional.

O corpo docente da instituição-alvo do estudo, percebeu na prática dos jogos digitais, a possibilidade de se trabalhar competências preconizadas na BNCC, conforme descrito em EF67EF01 e EF67EF02, já que a modalidade trouxe conhecimento, dinamismo, ludicidade e noção corporal, sem sair da esfera ética, do respeito e cumprimento das regras estabelecidas no contrato de conduta.

Alguns fatores elencados neste estudo ressaltam a importância dos jogos interclasses em formato digital para a formação dos estudantes, quais sejam: menor custo de execução, desonerando a instituição, a qual, a cada nova edição da competição em formato presencial, necessita adquirir materiais e equipamentos para a realização das práticas presenciais; ampliação do número de estudantes participantes, propiciando maior socialização; menor necessidade de colaboradores, pois a coordenação dos jogos é facilitada pelo fato de os jogos digitais permitirem maior autonomia dos jogadores, sem prescindir da presença física do árbitro; e, finalmente, a necessidade de uma infraestrutura menos onerosa para sua execução.

Um aspecto relevante da competição, em 2021, para a instituição e sua comunidade escolar, foi a mobilização do interesse de estudantes evadidos durante o ensino remoto emergencial, resgatando-se o vínculo e o elo desses estudantes com a unidade de educação, fragilizados durante a pandemia da COVID-19.

O evento ganhou repercussão nas mais diversas redes sociais, o que provocou o interesse e a procura, por parte de outras escolas da cidade, em entender mais sobre o modelo aplicado. No entanto, considerando este um projeto novo, é importante que seja avaliado previamente, como forma de solidificá-lo e dar-lhe continuidade. Somente após tal análise, poderá passar a compor, efetivamente, o quadro de eventos do calendário escolar, juntamente com os jogos tradicionais, que têm sua importância por trabalharem habilidades já reconhecidas, e incluir amplamente o público estudantil.

\section{Referências}

Erickson, F. (1992) "Etnographic microanalysis of interacion", In: MD. Lecompte, Edited by Millroy, W. L A and Preissle. J, The Handbook of Qualitative Research in Education, Academic Press, New York, p. 201-225. 
Green, J. and Castanheira, M. L (1980) "Etnografia interacional como uma lógica-deinvestigação dos processos de construção de oportunidades para aprendizagem" Edited by Spradley, J. Participant observation. Ny. Holt, Renehart \& Winston.

Hodges, C. and Moore, S. and Lockee, B. and Trust, T., \& Bond, A (2020) "The Difference Between Emergency Remote Teaching and Online Learning, ResearchGate", https://www.researchgate.net/publication/340535196_The_Difference_Between_Em ergency_Remote_Teaching_and_Online_Learning, 7 Julho 2021.

Laville, C e Dionne, Jean. (1999) "A construção do saber: manual de metodologia da pesquisa em ciências humanas". Porto Alegre: Artes Médicas; Belo Horizonte: UFMG.

McDermott, R. P., Gospodinoff, K., and Aron, J. (1978), "Criteria for an ethnographically adequate description of concerted actions and their contexts", In: Semiotica, v. 24, n. 3-4, p. 245-275.

Reverdito, R. S, et al. (2008) "Competições escolares: reflexão e ação em pedagogia do esporte para fazer a diferença na escola”, Pensar a prática, v. 11, n. 1, p. 37-45.

Rothan, H. A., and Byrareddy, S. N. (2020). "The epidemiology and pathogenesis of coronavirus disease (COVID-19) outbreak", Journal of Autoimmunity, v. 109, p. 102-433, 2020, https://pubmed.ncbi.nlm.nih.gov/32113704/, 7 Julho 2021.

Velavan, T. P., and Meyer, C. G. (2020) “The COVID-19 epidemic. Tropical Medicine \& International Health", v. 25, n. 3, p. 278-280, 2020, https://www.ncbi.nlm.nih.gov/pmc/articles/PMC7169770/, 7 Julho 2021. 